\title{
Vasomotor effects of L- and D-arginine in stenotic atheromatous coronary plaque
}

\author{
D Tousoulis, G J Davies, C Tentolouris, G Goumas, C Stefanadis, P Toutouzas
}

\begin{abstract}
Objective-To examine the effects of exogenous L- and D-arginine on coronary stenosis vasomotion in relation to stenosis morphology.

Design-Intracoronary infusions of normal saline, L- and D-arginine (50 and $150 \mu \mathrm{mol} / \mathrm{min}$ ), and glyceryl trinitrate $(250 \mu \mathrm{g}$ bolus) were given in 24 patients with coronary artery disease and stable angina. Coronary stenoses were classified as smooth or complex (irregular borders). The diameter of the coronary stenoses and their adjacent reference segments was measured by computed quantitative angiography.

Results-During L-arginine infusion a larger proportion of complex stenoses than smooth stenoses dilated by $\geqslant 10 \%(\mathrm{p}<0.01)$, and the magnitude of dilatation was greater at the site of complex stenoses $(\mathrm{p}<0.05)$. Irrespective of the type of morphology there was a positive correlation $(p<0.01)$ between the severity of stenoses and the magnitude of vasodilatation to L-arginine. The response to glyceryl trinitrate was similar in the two groups. No significant change was found in either group in response to D-arginine.

Conclusions-In patients with coronary artery disease, coronary stenoses - particularly those of complex morphology_dilate in response to the administration of L-arginine but not D-arginine. This finding is consistent with partial deficiency of the substrate for nitric oxide synthesis, L-arginine, at the site of complex stenoses.

(Heart 2001;86:296-301)
\end{abstract}

Cardiology Unit, Hippokration Hospital, Athens University Medical School, Athens, Greece

D Tousoulis

C Tentolouris

Keywords: endothelium; coronary artery disease; L-arginine, vasomotor tone

G Goumas

C Stefanadis

P Toutouzas

Imperial College

School of Medicine,

Hammersmith

Hospital, Du Cane

Road, London W12

ONN, UK

G J Davies

T Crake

Studies in humans have shown that vascular endothelium plays an important role in the regulation of blood flow by releasing endothelium dependent relaxing factors (EDRF) ${ }^{1-3}$ Nitric oxide, a major component of EDRF, is synthesised from the amino acid L-arginine by a family of enzymes through the L-argininenitric oxide pathway. ${ }^{46}$ The production of nitric oxide may be stimulated by L-arginine administration. ${ }^{1}$ It has also been shown that infusion of L-arginine into the brachial artery augments endothelium dependent forearm vasodilatation and reverses the defective enDr Davies dothelium dependent vasodilatation associated

Table 1 Clinical and angiographic characteristics of the patients

\begin{tabular}{|c|c|c|c|}
\hline & Total group & $L-A$ group & $D-A$ group \\
\hline Age (years) (mean (SD)) & $59 \quad(7)$ & (7) & (6) \\
\hline \multicolumn{4}{|l|}{ Sex } \\
\hline Male & 18 & 11 & 7 \\
\hline Female & 6 & 4 & 2 \\
\hline \multicolumn{4}{|l|}{ Previous myocardial infarct } \\
\hline (> 6 months) & 7 & 5 & 2 \\
\hline \multicolumn{4}{|l|}{ Risk factors } \\
\hline Hypertension & 8 & 5 & 3 \\
\hline Hyperlipidaemia & 15 & 9 & 6 \\
\hline Smoking & 12 & 8 & 4 \\
\hline Diabetes & 0 & 0 & 0 \\
\hline Family history & 14 & 9 & 5 \\
\hline $\begin{array}{l}\text { Mean plasma cholesterol } \\
(\mathrm{mmol} / \mathrm{l})(\text { mean }(\mathrm{SEM}))\end{array}$ & $6.53(0.31)$ & $6.42(0.44)$ & $6.84(0.26)$ \\
\hline $\begin{array}{l}\text { Mean plasma triglyceride } \\
(\mathrm{mmol} / \mathrm{l})(\text { mean }(\mathrm{SEM}))\end{array}$ & $1.85(0.16)$ & $1.74(0.19)$ & $2.05(0.25)$ \\
\hline \multicolumn{4}{|l|}{ Coronary artery disease } \\
\hline One vessel disease & 14 & 9 & 5 \\
\hline Two vessel disease & 7 & 4 & 3 \\
\hline Three vessel disease & 3 & 2 & 1 \\
\hline \multicolumn{4}{|l|}{ Number of lesions } \\
\hline$\geqslant 50 \%$ stenosis & 16 & 10 & 6 \\
\hline$<50 \%$ stenosis & 20 & 12 & 8 \\
\hline
\end{tabular}

Values are numbers of patients unless stated.

L-A, L-arginine; D-A, D-arginine. with an increased plasma low density lipoprotein concentration or hypercholesterolaemia. ${ }^{7-9}$ L-arginine administration improves the coronary blood flow response to acetylcholine in patients with normal coronary arteries and hypercholesterolaemia, ${ }^{10} 11$ enhances nitric oxide generation, and inhibits lesion formation after balloon angioplasty. ${ }^{12-14} \mathrm{~A}$ recent study ${ }^{15}$ showed vasodilatation of coronary stenoses with intracoronary L-arginine, and another ${ }^{16}$ demonstrated that arginine produced nonstereospecific peripheral vasodilatation.

It has been shown that complex coronary artery stenoses constrict more than smooth stenoses in response to LNMMA (Nmonomethyl L-arginine), indicating enhanced basal production of nitric oxide at the site of these stenoses. ${ }^{17}$ It is unknown whether this production can be modified by the administration of the substrate for nitric oxide synthase. Thus, in the present study we examined the coronary vasomotor effects of $\mathrm{L}-$ and D-arginine in patients with coronary artery disease and correlated the responses with stenosis morphology.

\section{Methods}

PATIENTS

We studied 24 patients (18 men, six women; mean (SD) age 59 (7) years) with chronic stable angina, coronary artery disease, and a positive treadmill exercise test result ( $\geqslant 0.1 \mathrm{mV} \mathrm{ST}$ segment depression) at between 5 and 7 METS using the modified Bruce protocol. The clinical characteristics of these patients are listed in table 1. Patients were excluded from the study if they had diabetes mellitus, recent myocardial infarction $(<6$ 
months), left ventricular hypertrophy (on echocardiography), left ventricular dysfunction (left ventricular ejection fraction $<50 \%$ ), or valvar heart disease. Hypercholesterolaemia was defined as a fasting serum total cholesterol $>200 \mathrm{mg} / \mathrm{dl}$ or serum triglyceride $>150 \mathrm{mg} / \mathrm{dl}$. Antianginal drug treatment was stopped 24 hours before the study. The patients were allowed to use sublingual glyceryl trinitrate as necessary, but no study was performed within three hours of its administration.

The protocol was approved by the research ethics committee and each patient gave written informed consent.

\section{PROTOCOL}

Following the diagnostic coronary angiogram, an optimal radiographic projection was selected and kept constant for subsequent angiograms. Two ECG leads were monitored continuously throughout the study. The following sequence of intracoronary infusions was applied in 15 patients ( 11 men, four women): (1) $0.9 \%$ saline $(2 \mathrm{ml} / \mathrm{min})$ for two minutes; (2) $50 \mu \mathrm{mol} / \mathrm{min}$ of $\mathrm{L}$-arginine for eight minutes; (3) $150 \mu \mathrm{mol} / \mathrm{min}$ of L-arginine for eight minutes; (4) a bolus of glyceryl trinitrate $(250 \mu \mathrm{g}$ in $2 \mathrm{ml}$ of saline). A syringe pump was used for continuous infusions. In nine patients (seven men, two women) with coronary artery disease, the same protocol was performed substituting 50 and $150 \mu \mathrm{mol} / \mathrm{min}$ of $\mathrm{D}$ - arginine for L-arginine.

Femoral arterial pressure and heart rate were recorded during the last 30 seconds of each infusion period. Angiography was performed after a hand injection of 6-8 $\mathrm{ml}$ non-ionic contrast medium at baseline, immediately after each infusion, and 2-3 minutes after glyceryl trinitrate. Before each angiogram, the catheter was emptied to avoid bolus administration of the infusate.

QUANTITATIVE CORONARY ANGIOGRAPHY

The arterial segments in each frame were analysed in random order using quantitative computed analysis with an automated edge contour detection analysis system (Computerised Angiographic Analysis System (CAAS), version 2V2; Pie Data Medical, Maastricht, The Netherlands).$^{18}$ End diastolic frames from each arteriogram were selected for analysis. The angiographic catheter was used as a scaling device and this, together with the pincushion distortion correction, allowed the diameters to be recorded as absolute values (expressed in $\mathrm{mm}$ ).

Stenoses were morphologically classified as smooth (concentric or eccentric) or "complex" by two blinded independent observers on the basis of visual inspection of arteriograms recorded in two orthogonal projections. This classification of stenosis was compared with that obtained by computed symmetry analysis (CAAS symmetry index $)^{1920}$ of the same coronary lesions. Concentric stenoses were defined as those producing symmetrical narrowing, with smooth borders or only very mild irregularity (symmetry index $>0.5-1$ ) that looked similar in orthogonal projections. Eccentric stenoses were defined as asymmetrical narrowing with smooth borders and a broad neck (symmetry index $0.0-\leqslant 0.5$ ). Complex stenoses were defined as asymmetric narrowing with irregular borders and/or overhanging edges (type II of Ambrose can colleagues) ${ }^{21} 22$ or with an "abrupt proximal face" ${ }^{23}$ or a "rough" or "sawtooth" component. ${ }^{23}$

Quantitative analysis of coronary arteriograms was carried out by two independent observers, who blindly reanalysed the films at a remote time for reproducibility of the method. No significant intraobserver or interobserver variability was found (analysis of variance $\mathrm{F}=0.37, \mathrm{p}=0.8)$

STATISTICAL ANALYSIS

Data are expressed as mean (SEM). Analysis of variance (ANOVA) and the Scheffé F test for repeated measures were used to compare serial changes in heart rate and blood pressure and in diameter of coronary stenoses. To test for differences in response of smooth and complex stenoses to L- and D-arginine and nitrates, a two way ANOVA for repeated measures was applied. Associations between responses to L-arginine and stenosis length, severity, and eccentricity ratio were assessed by performing linear regression analysis and calculating a correlation coefficient. Student's $t$ test was used to compare paired and unpaired data between groups, and the responses to glyceryl trinitrate and L- and D-arginine. A probability value of $\mathrm{p}<0.05$ (two tailed) was considered significant.

\section{Results}

The clinical and angiographic characteristics of the patients are listed in table 1 . Systolic aortic pressure and heart rate remained unchanged during intracoronary administration of L-arginine (blood pressure 143.2 (5.6) $v 146.2$ (5.9) $\mathrm{mm} \mathrm{Hg}$; heart rate 70.1 (1.8) v 72.5 (1.8) beats/min during baseline and L-arginine, respectively), and also during intracoronary administration of $\mathrm{D}$-arginine (blood pressure 146 (8) v 145 (9) $\mathrm{mm} \mathrm{Hg}$; heart rate 67.3 (2.6) $v 68.1$ (1.8) beats/min during baseline and D-arginine, respectively).

\section{STENOSIS MORPHOLOGY AND RESPONSE TO}

L-ARGININE AND GLYCERYL TRINITRATE

Twenty two of the 26 coronary stenoses (12 smooth, 10 complicated) observed in these 15 patients were suitable for quantitative analysis, and the results below refer to these stenoses. The severity of coronary stenoses for the whole group ranged from $22.2-86 \%$ luminal diameter reduction (mean 48.2 (3)\%). There were 10 stenoses of $\geqslant 50 \%$ : four smooth, six complex.

During L-arginine infusion a larger proportion of complex stenoses than smooth stenoses dilated by $\geqslant 10 \%(50 \% v 21 \%, \mathrm{p}<0.01)$. The magnitude of dilatation was greater $(p<0.05)$ at the site of complex stenoses than at the site of smooth stenoses, but was similar in their reference segments (table 2; fig 1). Irrespective of the type of morphology, there 
Table 2 Reactivity of coronary stenoses and their reference segments to intracoronary administration of $L$-arginine ( $L$-A) and nitrates

\begin{tabular}{|c|c|c|c|c|c|c|c|c|}
\hline \multirow[b]{3}{*}{ Morphology } & \multicolumn{8}{|c|}{ Minimum lumen diameter ( $\mathrm{mm}$ ) } \\
\hline & \multicolumn{4}{|l|}{ Stenoses } & \multicolumn{4}{|c|}{ Reference segments } \\
\hline & Baseline & $L A-50$ & $L A-150$ & Nitrates & Baseline & $L A-50$ & $L A-150$ & Nitrates \\
\hline Smooth $(n=12)$ & $1.66(0.08)$ & $\begin{array}{r}1.76(0.12) \\
+6.4 \quad(1.4) \%\end{array}$ & $\begin{aligned} & 1.80(0.14) \\
+ & 7.3 \quad(2.9) \%\end{aligned}$ & $\begin{array}{r}1.89(0.13) \\
+14.9 \quad(3.4) \%\end{array}$ & $2.92(0.16)$ & $\begin{aligned} & 3.05(0.18) \\
+ & 4.5 \quad(1.4) \%\end{aligned}$ & $\begin{array}{r}3.23(0.23) \\
+10.5(1.4) \%\end{array}$ & $\begin{array}{r}3.28(0.20) \\
+12.3(3.5) \%\end{array}$ \\
\hline Complex $(n=10)$ & $1.32(0.17)$ & $\begin{aligned} & 1.42(0.20) \\
&+7.1 \quad(3.2) \%\end{aligned}$ & $\begin{aligned} & 1.52(0.20) \\
&+13.7(2.5) \% \star\end{aligned}$ & $\begin{array}{r}1.60(0.20) \\
+19.4 \quad(2.3) \%\end{array}$ & $2.84(0.20)$ & $\begin{array}{r}3.04(0.20) \\
+6.3(2.9) \%\end{array}$ & $\begin{array}{r}3.10(0.20) \\
+10.4 \quad(2.4) \%\end{array}$ & $\begin{aligned} & 3.23(0.18) \\
&+10.4 \quad(2.5) \%\end{aligned}$ \\
\hline
\end{tabular}

Values are mean (SEM).

${ }^{\star} \mathrm{p}<0.05 v$ smooth stenoses.

LA-50, $50 \mu \mathrm{mol} \mathrm{L-arginine/min;} \mathrm{LA-150,} 150 \mu \mathrm{mol} \mathrm{L-arginine/min.}$

was a positive correlation $(\mathrm{p}<0.01)$ between the severity of stenoses and the magnitude of the vasomotor response to L-arginine (fig 2). A similar proportion of smooth and complex stenoses showed $\geqslant 10 \%$ dilatation with glyceryl trinitrate ( $67 \% v 80 \%$, NS), and the magnitude of the response was similar in the two groups (table 2). In response to $150 \mu \mathrm{mol} / \mathrm{min}$
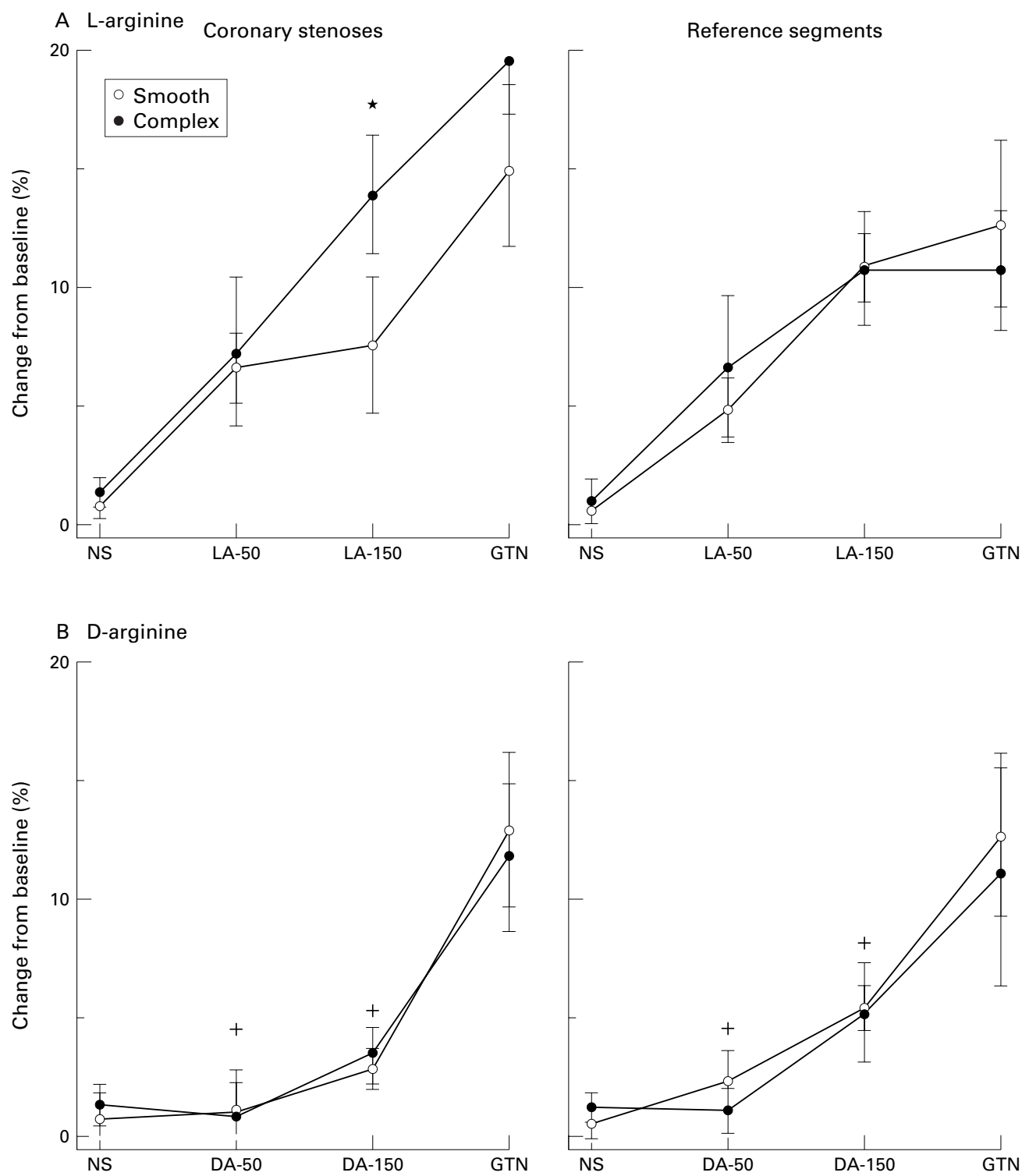

Figure 1 Graphs showing mean per cent change of luminal diameter from baseline in smooth and complex stenoses and their reference segments in response to $L$ - and $D$-arginine. In response to $L$-arginine the magnitude of dilatation was greater $\left({ }^{*} p<0.05\right)$ at the site of complex stenoses than at the site of smooth stenoses, but was similar in the reference segments. In response to D-arginine the magnitude of dilatation was significantly less than that of $L$-arginine $(+p<0.05)$. NS, normal saline; LA-50, L-arginine $50 \mu \mathrm{mol} / \mathrm{min} ; \mathrm{LA}-150$, L-arginine $150 \mu \mathrm{mol} / \mathrm{min} ; D A-50$, D-arginine $50 \mu \mathrm{mol} / \mathrm{min} ; D A-150$, D-arginine $150 \mu \mathrm{mol} / \mathrm{min} ; \mathrm{GTN}$, glyceryl trinitrate. 

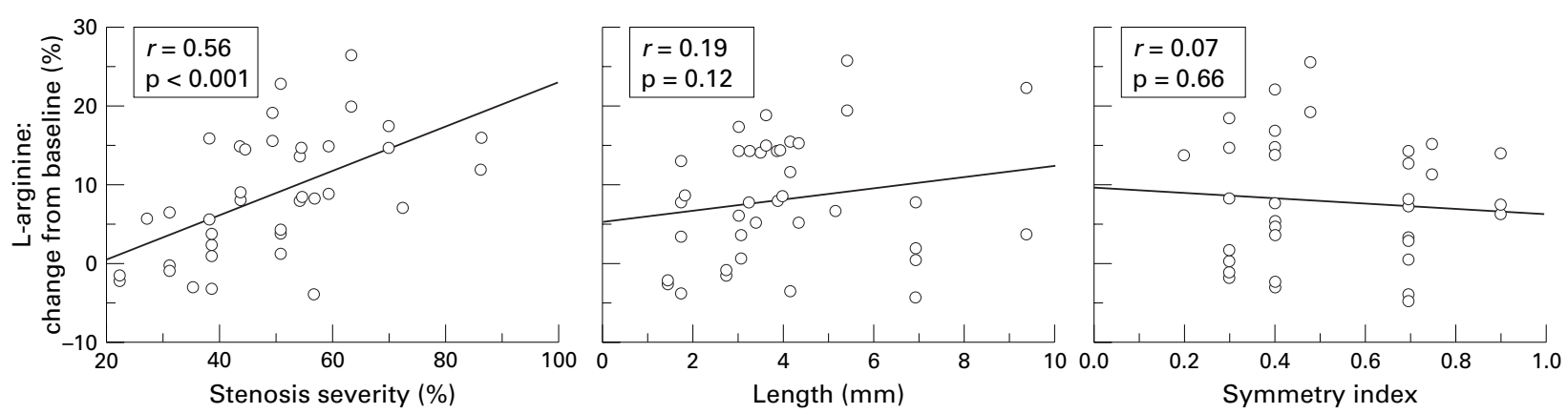

Figure 2 Correlations between stenosis severity (left panel), stenosis length (middle panel), stenosis symmetry index (right panel), and the magnitude of $L$-arginine response, expressed as per cent change of coronary artery diameter from baseline. Linear regression analysis showed a significant correlation between stenosis severity and L-arginine response.

L-arginine, there was no difference in the magnitude of dilatation of coronary stenoses between smokers and non-smokers (11.2 $(2.2) \% \quad v 10.2$ (5.2)\%, respectively; NS), between hypercholesterolaemic and nonhypercholesterolaemic patients $(10.2(2.8) \% v$ $11.9(3.0) \%$; NS), or between hypertensive and non-hypertensive patients (10.7 (3.5)\% $v 11.2$ (2.5) $\%$; NS).

STENOSIS MORPHOLOGY AND RESPONSE TO D-ARGININE AND GLYCERYL TRINITRATE Fourteen of the 15 coronary stenoses (eight smooth, six complex) observed in these nine patients were suitable for quantitative analysis, and the results below refer to these stenoses. The severity of coronary stenoses for the whole group ranged from $30.3-71.7 \%$ luminal diameter reduction (mean 46.8 (3.6)\%). There were six stenoses of $\geqslant 50 \%$ : three smooth, three complex.

There was no significant change in the diameter of smooth and complex stenoses, or of their reference segments, in response to D-arginine (table 3). The magnitude of dilatation in response to D-arginine was significantly less than after L-arginine for coronary segments and stenoses (fig 1; table 3). There was no difference in the response of smooth and complex stenoses or their reference segments to glyceryl trinitrate (fig 1 ; table 3 ). In response to $150 \mu \mathrm{mol} / \mathrm{min} \mathrm{D}$-arginine there was no difference in the magnitude of dilatation of coronary stenoses between smokers and nonsmokers $(2.02(0.4) \%$ v $2.3(0.6) \%$ respectively; NS), between hypercholesterolaemic and non-hypercholesterolaemic patients (1.76 $(0.4) \%$ v $3.16(0.3) \%$; NS), or between hypertensive and non-hypertensive patients (1.95 $(0.7) \%$ v $3.32(0.4) \%$; NS).

\section{Discussion}

In this study we investigated the effects of Land D-arginine and the endothelium independent vasodilator glyceryl trinitrate in patients with coronary artery disease and stable angina. Complex stenoses were more likely to dilate in response to L-arginine than smooth stenoses, and they dilated to a greater degree. There was no significant response of either type of stenosis to D-arginine. The response to glyceryl trinitrate was independent of stenosis morphology.

\section{PLAQUE MORPHOLOGY AND NITRIC OXIDE} ACTIVITY

Clinical studies have suggested that stenoses with a complex morphology rapidly progress to total or subtotal occlusion and are often the substrate for acute coronary syndromes. ${ }^{21-24}$ These stenoses are not only morphologically complex but also have more complex histology and contain a large variety of cell types including abundant macrophages. ${ }^{24-28}$ They are also more complex functionally, as exemplified by an enhanced vasoconstrictor response to serotonin $^{19}$ and other vasoconstrictor stimuli. ${ }^{29}$ Results of our previous studies showing enhanced constriction in response to LNMMA, suggestive of increased nitric oxide synthase activity, indicate that the pathologically enhanced vasomotor responsiveness is also expressed in the endogenous vasodilator mechanisms within these stenoses. ${ }^{17}{ }^{30}$ This finding is consistent with the observation of inducible nitric oxide synthase immunoreactivity within complex atherosclerotic coronary artery stenoses. The cellular localisation of this nitric oxide synthase is unclear but it could possibly be in macrophages and smooth muscle cells, and it has been found in the endothelium of the new microvessels in the wall of the artery

Table 3 Reactivity of coronary stenoses and their reference segments to intracoronary administration of $D$-arginine (D-A) and nitrates

\begin{tabular}{|c|c|c|c|c|c|c|c|c|}
\hline \multirow[b]{3}{*}{ Morphology } & \multicolumn{8}{|c|}{ Minimum lumen diameter ( $\mathrm{mm}$ ) } \\
\hline & \multicolumn{4}{|l|}{ Stenoses } & \multicolumn{4}{|c|}{ Reference segments } \\
\hline & Baseline & $D A-50$ & $D A-150$ & Nitrates & Baseline & $D A-50$ & $D A-150$ & Nitrates \\
\hline Smooth $(\mathrm{n}=8)$ & $1.64(0.11)$ & $\begin{array}{c}1.66(0.11) \\
+0.8 \quad(1.0) \%\end{array}$ & $\begin{array}{c}1.68(0.11) \\
+2.3(0.7) \%\end{array}$ & $\begin{array}{r}1.81(0.11) \\
+10.7(2.7) \%\end{array}$ & $2.82(0.15)$ & $\begin{array}{r}2.88(0.18) \\
+2.1 \quad(1.0) \%\end{array}$ & $\begin{array}{cc} & 2.96(0.16) \\
+4.6 \quad(0.8) \%\end{array}$ & $\begin{array}{r}3.10(0.14) \\
+10.7(2.9) \%\end{array}$ \\
\hline Complex $(n=10)$ & $1.51(0.14)$ & $\begin{aligned} & 1.52(0.14) \\
&+0.6 \quad(1.6) \%\end{aligned}$ & $\begin{aligned} & 1.55(0.15) \\
+ & 2.8(1.0) \%^{\star}\end{aligned}$ & $\begin{array}{r}1.66(0.17) \\
+9.7 \quad(2.6) \%\end{array}$ & $2.94(0.13)$ & $\begin{array}{r}2.98(0.14) \\
+1.0 \quad(0.8) \%\end{array}$ & $\begin{aligned} & 3.06(0.10) \\
+ & 4.4 \quad(1.7) \%\end{aligned}$ & $\begin{array}{r}3.19(0.15) \\
+9.3(3.8) \%\end{array}$ \\
\hline
\end{tabular}

Values are mean (SEM)

DA-50, $50 \mu \mathrm{mol} \mathrm{D}$-arginine/min; DA-150, $150 \mu \mathrm{mol} \mathrm{D-arginine/min.}$ 
around the atheromatous plaque. ${ }^{31}$ Such neovascularisation of atheromatous plaques is well documented.

The resting tone appears to be similar for both smooth and complex stenoses, as evidenced by the similar magnitude of dilatation in response to nitrate administration. However, our results provide further evidence that complex plaques are active structures. There may be a link between enhanced inducible nitric oxide activity (produced by macrophages) and plaque instability. Macrophages and the $\mathrm{T}$ lymphocytes may produce cytokines that induce nitric oxide synthase. ${ }^{27}{ }^{32}$ Furthermore, metalloproteinases produced in macrophages in vulnerable regions of complex atherosclerotic plaques may weaken the fibrous cap of the plaque, leading to rupture and thrombosis. ${ }^{25} 33$ There is also growing evidence that macrophages may be involved in smooth muscle cell death by apoptosis which occurs in atheromatous plaques ${ }^{34}$ and that they initiate or enhance the degradation of collagen. ${ }^{35}$

PLAQUE MORPHOLOGY AND RESPONSE TO L- AND D-ARGININE

L-arginine, whether given intravenously or intra-arterially, can reduce vascular tone..$^{15} 356$ The mechanism by which it exerts its vasodilator effects is controversial, ${ }^{16}$ but the L-arginine-NO synthase nitric oxide pathway appears to be particularly important. The L isomer of arginine is a substrate for the endothelial cell and for both inducible (in macrophages and foam cells) and smooth muscle cell isoforms of the enzyme nitric oxide synthase. ${ }^{1}$ These enzymes convert L-arginine to citrulline and nitric oxide. The $\mathrm{D}$ isomer of arginine is not a substrate for nitric oxide synthase. ${ }^{1}$

It has been suggested that diseased arteries may be relatively deficient in the substrate L-arginine. ${ }^{133738}$ Apart from limiting nitric oxide production, substrate deficiency could lead to the generation of superoxide by both inducible and endothelial nitric oxide synthase. ${ }^{39}$ The results of our study are consistent with a relative deficiency of L-arginine at the site of stenoses in diseased coronary arteries, particularly within stenoses with complex morphology. They are a further indication that complex morphology is a marker of increased functional activity and they are consistent with enhanced nitric oxide activity. This could represent a natural compensatory mechanism to counteract the predisposition to constriction generated by atherosclerotic disease. A recent study $^{16}$ showed that parenteral arginine produced non-stereospecific peripheral vasodilatation and improved endothelium dependent vasodilatation in patients with stable coronary artery disease by stimulation of insulin dependent nitric oxide release or by non-enzymatic nitric oxide generation. Other studies ${ }^{40}{ }^{41}$ also showed a non-stereospecific arteriolar and venous dilatation accompanied by hypotension in normal subjects at high parenteral concentrations of both L- and D-arginine. In contrast, intravenous $\mathrm{L}$-arginine but not $\mathrm{D}$-arginine improved forearm dilatation in hypercholesterolaemic subjects in response to methacholine. ${ }^{7}$ Furthermore, in coronary arteries, intra-arterial L-arginine but not D-arginine improved the acetylcholine responses in hypercholesterolaemic and atherosclerotic patients. ${ }^{104} 43$ Panza and colleagues showed that availability of the substrate for production of nitric oxide is a rate limiting step for endothelial dependent vascular relaxation in normal healthy subjects but not in hypertensive patients. ${ }^{44}$ Oral arginine has also been shown to improve branchial artery flow mediated dilatation in hypercholesterolaemic patients but not in normal individuals. ${ }^{45}$ We found that intracoronary L-arginine significantly dilated atherosclerotic arteries and stenoses in patients with stable angina. Although there was a positive correlation between the severity of stenoses and the magnitude of the vasomotor response to L-arginine, it was weak $(r=0.56)$.

The high intracellular concentrations of L-arginine found in experimental studies ${ }^{12-14}$ suggest that a deficiency of this substrate may not be responsible for reduced availability of nitric oxide. Thus other mechanisms should be postulated to explain the beneficial effects of $\mathrm{L}$-arginine. These include reversal of inhibitory effects of L-glutamine on L-arginine; counteraction of inhibitory effects of naturally occurring asymmetric dimethyl arginine (ADMA); antioxidant effects; insulin release; and nonenzymatic generation of nitric oxide by L-arginine. ${ }^{1642}$

\section{CONCLUSIONS}

In patients with coronary artery disease, complex coronary stenoses dilate more than smooth stenoses after L-arginine administration, but neither respond to $\mathrm{D}$-arginine. This is consistent with partial deficiency of the substrate for nitric oxide synthesis at the site of atheromatous stenoses, particularly when they are of complex morphology.

1 Moncada S, Palmer RMJ, Higgs EA. Nitric oxide: physiology pathology and pharmacology. Pharmacol Rev 1991;43:109-42.

2 Vanhoutte PM. The endothelium. Modulator of vascular smooth muscle tone. N Engl F Med 1988;319:512-13.

3 Luecher TF, Richard V, Tschudi M, et al. Endothelial control of vascular tone in large and small coronary arteries. $\mathcal{F}$ Am Coll Cardiol 1990;15:512-27.

4 Palmer RMJ, Ashton DS, Moncada S. Vascular endothelial cells synthesize nitric oxide from L-arginine. Nature 1988; 333:664-6.

5 Palmer RMJ, Ferrige AG, Moncada S. Nitric oxide release accounts for the biological activity of endothelium-derived relaxing factor. Nature 1987;327:524-6.

6 Rees DD, Palmer RMJ, Hodson HF, et al. A specific inhibitor of nitric oxide formation from L-arginine attenuates tor of nitric oxide formation from L-arginine attenuates 96:418-24.

7 Creager MA, Gallagher SM, Girerd XJ, et al. L-arginine improves endothelium-dependent vasodilation in hypercholesterolemic humans. f Clin Invest 1992;90:1248-53.

8 Imaizumi $\mathrm{T}$, Hirooka $\mathrm{Y}$, Masaki $\mathrm{H}$, et al. Effects of L-arginine on forearm vessels and responses to acetylcholine. Hypertension 1992;20:511-17.

9 Jeremy RW, McCarron H, Sullivan D. Effects of dietary L-arginine on atherosclerosis and endothelium-dependent vasodilation in the hypercholesterolemic rabbit: response according to treatment duration, anatomic site, and sex. Circulation 1996;94:498-506.

10 Drexler H, Zeiher AM, Meinzer K, et al. Correction of endothelial dysfunction in coronary microcirculation of hypercholesterolemic patients by L-arginine. Lancet 1991; 338: $1546-50$.

11 Egashira K, Hirooka Y, Kuga T, et al. Effects of L-arginine supplementation on endothelium-dependent coronary vasodilation in patients with angina pectoris and normal coronary angiograms. Circulation 1996;94:130-4. 
12 Girerd XJ, Hirsch AT, Cooke JP, et al. L-arginine augments endothelium-dependent vasodilation in cholesterol-fed endothelium-dependent vasodilatio
rabbits. Circ Res 1990;67:1301-8.

13 Aji W, Ravalli S, Szabolcs M, et al. L-arginine prevents xanthoma development and inhibits atherosclerosis in LDI receptor knockout mice. Circulation 1997;95:430-7.

14 Cooke JP, Singer AH, Tsao PS, et al. Anti-atherogenic effects of L-arginine in hypercholesterolemic rabbit. $\mathcal{J}$ Clin Invest 1992;90:1168-72.

15 Tousoulis D, Davies G, Tentolouris C, et al. Coronary stenosis dilation induced by L-arginine. Lancet 1997;349:1812-13.

16 Quyyumi A. Does acute improvement of endothelia dysfunction in coronary artery disease improve myocardial ischemia? A double-blind comparison of parenteral D- and L-arginine. 7 Am Coll Cardiol 1998;32:904-11.

17 Tousoulis D, Tentolouris C, Crake T, et al. Complex stenosis morphology and vasomotor responses to inhibition of nitric oxide synthesis. Heart 2000;84:529-34.

18 Reiber JHC, Serruys PW, Koouman C, et al. Assessment of short-, medium, and long-term variations in arterial short-, medium, and long-term variations in arterial ary cineangiograms. Circulation 1985;71:280-8.

19 Tousoulis D, Davies G, McFadden E, et al. Coronary vasomotor effects of setotonin in patients with angina Relationship to coronary stenosis morphology. Circulation 1993;88:1518-26.

20 Kaski JC, Tousoulis D, Haider WA, et al. Reactivity of eccentric and concentric stenoses in chronic stable angina. f Am Coll Cardiol 1991;17:627-33.

21 Ambrose JA, Winters SL, Arora RR, et al. Coronary angiographic morphology in myocardial infarction: a link between the pathogenesis of unstable angina and myocardial infarction. 7 Am Coll Cardiol 1985;6:1233-8.

22 Ambrose JA, Winters SL, Arora RR, et al. Angiographic evolution of coronary artery morphology in unstable angina. $7 \mathrm{Am}$ Coll Cardiol 1986;7:472-8.

23 Ellis S, Alderman EL, Cain K, et al. Morphology of left anterior descending coronary territory lesions as a predictor of anterior myocardial infarction: a CASS registry study. 7 Am Coll Cardiol 1989;13:1481-91.

24 Tousoulis D, Davies G, Crake T, et al. Angiographic characteristics of the infarct and non-infarct related stenoses in teristics of the infarct and non-infarct related stenoses in
patients with stable angina progressed to acute myocardial infarction. Am Heart f 1998;136:382-8.

25 Libby P, Geng YJ, Aikawa M, et al. Macrophages and atherosclerosis plaque stability. Curr Opin Lipidol 1996;7: $330-5$

26 Galis ZS, Sukhova GK, Lark MW, et al. Increased expression of matrix metalloproteinases and matrix degrading activity in vulnerable regions of human atherosclerotic plaques. $\mathcal{F}$ Clin Invest 1994;94:2493-503.

27 Dollery CM, McEwan JR, Henney AM. Matrix metalloproteinases and cardiovascular disease. Circ Res 1995:77:863-8.

28 Sukhova GK, Schonbeck U, Rabkin E, et al. Evidence for increased collagenolysis by interstitial collagenases- 1 and -3 in vulnerable human atheromatous plaques. Circulation 1999;99:2503-9.

29 Tousoulis D, Crake T, Kaski JC, et al. Enhanced vasomotor responses of complex stenoses to acetylcholine in patients with chronic stable angina. Am f Cardiol 1995;75:725-8.
30 Tousoulis D, Davies GJ, Tentolouris C, et al. Effects of inhibition of nitric oxide synthesis in patients with coronary artery disease and stable angina. Eur Heart f 1997;18:608-13.

31 Buttery LDK, Springall DR, Chester AH, et al. Inducible NO synthase is present within human atherosclerotic lesions and promotes the formation and activity of peroxynitrite. Lab Invest 1996;75:77-85.

32 Esaki T, Hayashi T, Muto E, et al. Expression of inducible nitric oxide synthase in T lymphocytes and macrophages of cholesterol-fed rabbits. Atherosclerosis 1997;128:39-46.

33 Schonbeck U, Mach F, Sukhova GK, et al. Regulation of matrix metalloproteinase expression in human vascular smooth muscle cells by T-lympocytes. Circ Res 1997;81:448-54.

34 Saraste A, Pulkki K, Kallajoki M, et al. Apoptosis in human acute myocardial infarction. Circulation 1997;95:320-3.

35 Hirooka Y, Egashira K, Imaizumi T, et al. Effect of L-arginine on acetylcholine-induced endotheliumdependent vasodilation differs between the coronary and dependent vasodilation differs between the coronary and 1994;24:948-55.

36 Thorne S, Mullen M, Clarkson P, et al. Early endothelial dysfunction in adults and risk from atherosclerosis: different responses to L-arginine. $\mathcal{F} \mathrm{Am}$ Coll Cardiol 1998;32:110-16.

37 Cooke JP, Andon NA, Girerd XJ, et al. Arginine restores cholinergic relaxation of hypercholesterolemic rabbit thoracic aorta. Circulation 1991;83:1057-62.

38 Boger R, Bode-Boger SM, Thiele W, et al. Restoring vascular nitric oxide formation by L-arginine improves the symptoms of intermittent claudication in patients with peripheral arterial occlusive disease. $7 \mathrm{Am}$ Coll Cardiol 1998;32:13336-44.

39 Hogg N, Darley-Usman VM, Wilson MT, et al. Production of hydroxyl radicals from the simultaneous generation of superoxide and nitric oxide. Biochem f 1992;281:419-24.

40 Bode-Boger SM, Boger RH, Creutzig A, et al. L-arginine infusion decreases peripheral arterial resistance and inhibits platelet aggregation in healthy subjects. Clin Sci 1994;87:303-10.

41 Calver A, Collier J, Vallance P. Dilator actions of arginine in human peripheral vasculature. Clin Sci 1991;81:695-700.

42 Quyyumi A, Dakak N, Diodati J, et al. Effect of L-arginine on human coronary endothelial-dependent and physiologic vasodilation. 7 Am Coll Cardiol 1997;30:1220-7.

43 Dubois-Rande JL, Zelinsky R, Roudot F, et al. Effects of infusion of L-arginine into the left anterior descending coronary artery on acetylcholine-induced vasoconstriction of
human atheromatous coronary arteries. Am 7 Cardiol 1992;70:1269-75.

44 Panza JA, Casino PR, Badar DM, et al. Effect of increased availability of endothelium-derived nitric oxide precursor on endothelium-dependent vascular relaxation in normal subjects and in patients with essential hypertension. Circulation 1993;87:1475-81.

45 Clarkson P, Adams MR, Powe AJ, et al. Oral L-arginine improves endothelium-dependent dilation in hypercholesterolemic young adults. F Clin Invest 1996;97:1989-94.

\section{7th European Forum on Quality Improvement in Health Care}

\section{1-23 March 2002 \\ Edinburgh, Scotland}

We are delighted to announce this forthcoming conference in Edinburgh. Authors are invited to submit papers (call for papers closes on Friday 5 October 2001) and delegate enquiries are welcome.

The themes of the Forum are:

- Leadership, culture change, and change management

- Achieving radical improvement by redesigning care

- Health policy for lasting improvement in health care systems

- Patient safety

- Measurement for improvement, learning, and accountability

- Partnership with patients

- Professional quality: the foundation for improvement

- Continuous improvement in education and training

- People and improvement.

Presented to you by the BMJ Publishing Group (London, UK) and Institute for Healthcare Improvement (Boston, USA). For more information contact: quality@bma.org.uk or look at the website www.quality.bmjpg.com. Tel: +44 (0)20 7383 6409; fax: +44 (0)20 73736869 . 